This item was submitted to Loughborough's Research Repository by the author.

Items in Figshare are protected by copyright, with all rights reserved, unless otherwise indicated.

\title{
Analysis of the validity of the mathematical assumptions of electrical impedance tomography for human head tissues
}

\section{PLEASE CITE THE PUBLISHED VERSION}

https://doi.org/10.1088/2057-1976/abe190

\section{PUBLISHER}

IOP Publishing

\section{VERSION}

VoR (Version of Record)

\section{PUBLISHER STATEMENT}

This is an Open Access Article. It is published by IOP under the Creative Commons Attribution 4.0 Unported Licence (CC BY). Full details of this licence are available at: http://creativecommons.org/licenses/by/4.0/

\section{LICENCE}

CC BY 4.0

\section{REPOSITORY RECORD}

Williams, Toby, Kaddour Bouazza-Marouf, Massimiliano Zecca, and Alex Green. 2021. "Analysis of the Validity of the Mathematical Assumptions of Electrical Impedance Tomography for Human Head Tissues". Loughborough University. https://hdl.handle.net/2134/14062004.v1. 
PAPER • OPEN ACCESS

Analysis of the validity of the mathematical assumptions of electrical impedance tomography for human head tissues

To cite this article: Toby Williams et al 2021 Biomed. Phys. Eng. Express 7025011

View the article online for updates and enhancements.

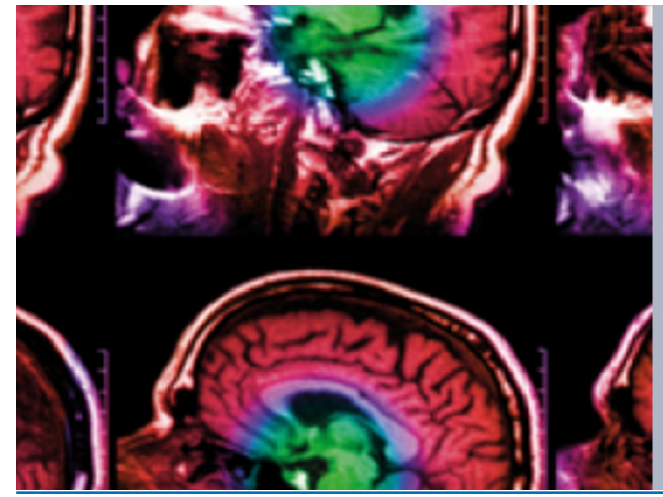




\title{
Biomedical Physics \& Engineering Express
}

\section{PAPER}

CrossMark

\section{Analysis of the validity of the mathematical assumptions of electrical impedance tomography for human head tissues}

RECEIVED

28 July 2020

REVISED

19 January 2021

ACCEPTED FOR PUBLICATION

29 January 2021

PUBLISHED

8 February 202

Original content from this work may be used under the terms of the Creative

Commons Attribution 4.0 licence.

Any further distribution of this work must maintain

attribution to the author(s) and the title of the work, journal citation and DOI.

\author{
Toby Williams ${ }^{1, *}$ (iD , Kaddour Bouazza-Marouf ${ }^{1}$, Massimiliano Zecca $^{1}$ (iD) and Alexander L Green \\ 1 Wolfson School of Mechanical, Electrical, and Manufacturing Engineering, Loughborough University, Leicestershire, LE11 3TU, United \\ Kingdom \\ 2 Nuffield Department of Surgical Sciences, University of Oxford, Oxfordshire, OX3 9DU, United Kingdom \\ * Author to whom any correspondence should be addressed. \\ E-mail: t.williams@lboro.ac.uk, k.bouazza-marouf@lboro.ac.uk,m.zecca@lboro.ac.uk and alex.green@nds.ox.ac.uk \\ Keywords: Bioimpedance, Conductivity, Permittivity, Electrical Impedance Tomography(EIT) \\ Supplementary material for this article is available online
}

Abstract

Objective: To determine the validity of the key mathematical assumptions used in electrical impedance tomography for human head tissues. Approach:Conductivity and permittivity data collected from available literature for each tissue within the human head have been evaluated and critiqued. The most relevant dielectric tissue data for each tissue was then used to assess the validity of the mathematical assumptions of electrical impedance tomography in terms of their suitability for human head imaging in order to estimate related errors. Main Results:For induced currents with frequencies greater than $200 \mathrm{~Hz}$ the internal current source density is negligible. The assumption that magnetic effects are negligible is valid to an error of $1.7 \%$ for human head tissues for frequencies below $1 \mathrm{MHz}$. The capacitive effects are negligible for CSF, dura mater, blood, bone (cortical), and deep tissue skin for frequencies less than $3.2 \mathrm{MHz}, 320 \mathrm{kHz}, 25 \mathrm{kHz}, 3.2 \mathrm{kHz}$, and $130 \mathrm{~Hz}$ respectively. However, the capacitive effects are not negligible for brain tissues, as the minimum error for brain tissues across the frequency range of $10 \mathrm{~Hz}$ to $100 \mathrm{GHz}$ is $6.2 \%$ at $800 \mathrm{~Hz}$, and the maximum error is $410 \%$ at $20 \mathrm{GHz}$. Significance:It is often assumed that the mathematical reduction of the base equations is valid for human head tissues over a broad frequency range; this study shows that these assumptions are not true for all tissues at all frequencies. False assumptions will result in greater errors and local distortions within tomographic images of the human head using electrical impedance tomography. This study provides the relationships between injected current frequency and the validity of the mathematical assumptions for each individual tissue, providing greater awareness of the magnitude of possible distortions.

\section{Introduction}

Electrical impedance tomography (EIT) is a noninvasive, non-radiating and non-ionising technique capable of producing tomographic images of interior sections of a body. The technique involves injection of small alternating currents ( $\leqslant 10 \mathrm{~mA}$ for medical applications) onto the surface of a body using electrocardiogram (ECG) type electrodes and measuring the resulting potentials around the surface (Nunez and Srinivasan 2006). Inhomogeneities that have a different conductivity compared to a homogeneous background cause the development of unique current paths and specific sets of potential distributions. Voltage reading electrodes measure boundary potentials allowing for the tissue distribution within the body to be estimated.

The calculation used for the estimation of the conductivity distribution from known boundary voltage measurements is referred to as the inverse problem. The inverse problem is severely ill-posed and nonlocal, relying upon several forms of regularisation and a priori information to be able to reconstruct the conductivity distribution images. Therefore, a forward solution is first solved to provide an estimation of the boundary potentials that should be developed 
supposing that the material distribution within the body is as anticipated. These predicted boundary potentials are then compared with the actual (measured) boundary potentials and the inverse solution is then used to minimize the error signal and generate an image of the anomalous conductivity distribution.

To solve the forward solution for EIT either a measurement of the boundary potentials of the body before the development of an anomaly is used, or an accurate model of the body is used in a computer simulation to estimate the boundary potentials (without an anomaly). For many medical applications however, neither of these options are practical due to large variations in shape and size of organ systems because of gender, age, ethnicity, etc. This has lead to the use of multi-frequency EIT (MFEIT), whereby measurements at different frequencies are taken with the anomaly in place, then compared against one another to form the final conductivity distribution image. EIT relies on the differentiation of tissues; therefore, it is important to know how the bioimpedance of tissues alter over different frequency ranges. This is critical for both the development imaging algorithms and phantom tissue models used for development testing.

In order to determine the presence and location of an anomaly using EIT it is critical to understand the relationship between the admittivity and the electrical input frequency of the anomaly and its surrounding tissue. By knowing the change in conductivity of tissues between two known frequencies, each voxel of the change in conductivity matrix, $\Delta \sigma$, can be assigned an estimated tissue, whereby:

$$
\begin{gathered}
\Delta \boldsymbol{\sigma}=A^{\dagger} \mathbf{V}, \\
\Delta \mathbf{V}_{F D A_{i}}=\mathbf{V}_{f_{i}}-\mathbf{V}_{f_{i-1}} .
\end{gathered}
$$

where $A^{\dagger}$ is the pseudo-inverse of the sensitivity matrix, $\mathbf{V}$ is either the matrix of boundary voltages or the difference in boundary voltages between two frequencies, $\Delta \mathbf{V}_{F D A_{i}}$ is the frequency difference adjacent matrix of boundary voltages for two subsequent frequencies and, $\mathbf{V}_{f_{i}}$ and $\mathbf{V}_{f_{i-1}}$ are boundary voltage matrices at frequencies $f_{i}$ and $f_{i-1}$ respectively.

This paper assesses the reliability of the measurement methods used and the agreement between data sets for published dielectric tissue data. The best published data are identified, based on their measurement methodologies and their agreement with other collected data, and used to assess the validity of the mathematical assumptions made in the formulation of the base equations for EIT in the identification of different tissues in the human head across a broad frequency range. Section 2 introduces the different types of dielectric measurement methods for tissue analysis, introduces the effect of a tissue's physiological condition on the measured dielectric results, and discusses the suitability of each dielectric data set available from the literature for each tissue constituting the human head. Section 3 assesses the validity of the mathematical assumptions made for the EIT conductivity mapping for each biological tissue. Concluding remarks are given in Section 4 on the overall usability and reliability of existing published data as well as potential measurements to be undertaken to improve the understanding of the anisotropy of different tissues.

\section{Dielectric properties of head tissues}

The majority of in vivo experimental human tissue data has not been recorded for the whole desired bandwidth of frequencies that are employed by various EIT strategies. The majority of EIT systems operate within a bandwidth of $100 \mathrm{~Hz}$ to $1 \mathrm{MHz}$. Many experimental studies on human tissue have been conducted at either low frequencies close to or including $\mathrm{dc}$, or in the $\mathrm{GHz}$ range. In these instances it is common to supplement live human tissue data with that of autopsy material or excised animal tissue, where live human tissue data is lacking or unobtainable.

In this section experimental results from relevant studies are reviewed and critiqued, with the aim to provide a compilation of the most relevant and accurate data for the frequency response of different tissues available.

\subsection{Measurement methodology}

There are different methods of conducting impedance analysis; these depend on the number of terminal electrodes used for the analysis, either two, three, or four electrodes. Both the two- and three-terminal methods record voltages on current carrying electrodes. However, both of these methods suffer in that the electrode-material contact impedance and electrode polarisation caused by the flow of current directly affects the bioimpedance measurement taken. The three-terminal method attempts to mitigate the effects caused by active current flow through a voltage read electrode by utilising a passive reference electrode, but is still relatively susceptible to current flow effects, based on the contact tissue's properties and nonuniformity between electrode materials. The fourterminal method records boundary voltages on two non-current carrying electrodes. This negates contact impedance errors if the input impedance of the voltage recording amplifiers is sufficiently high as to allow negligible current to be drawn across the recording electrodes (Horesh 2006). It is therefore, important to understand how the dielectric properties of biological tissues have been collected, as two-terminal data may have either not accounted for the presence of contact impedance, or incorrectly measured the effect of contact impedance in their results. 


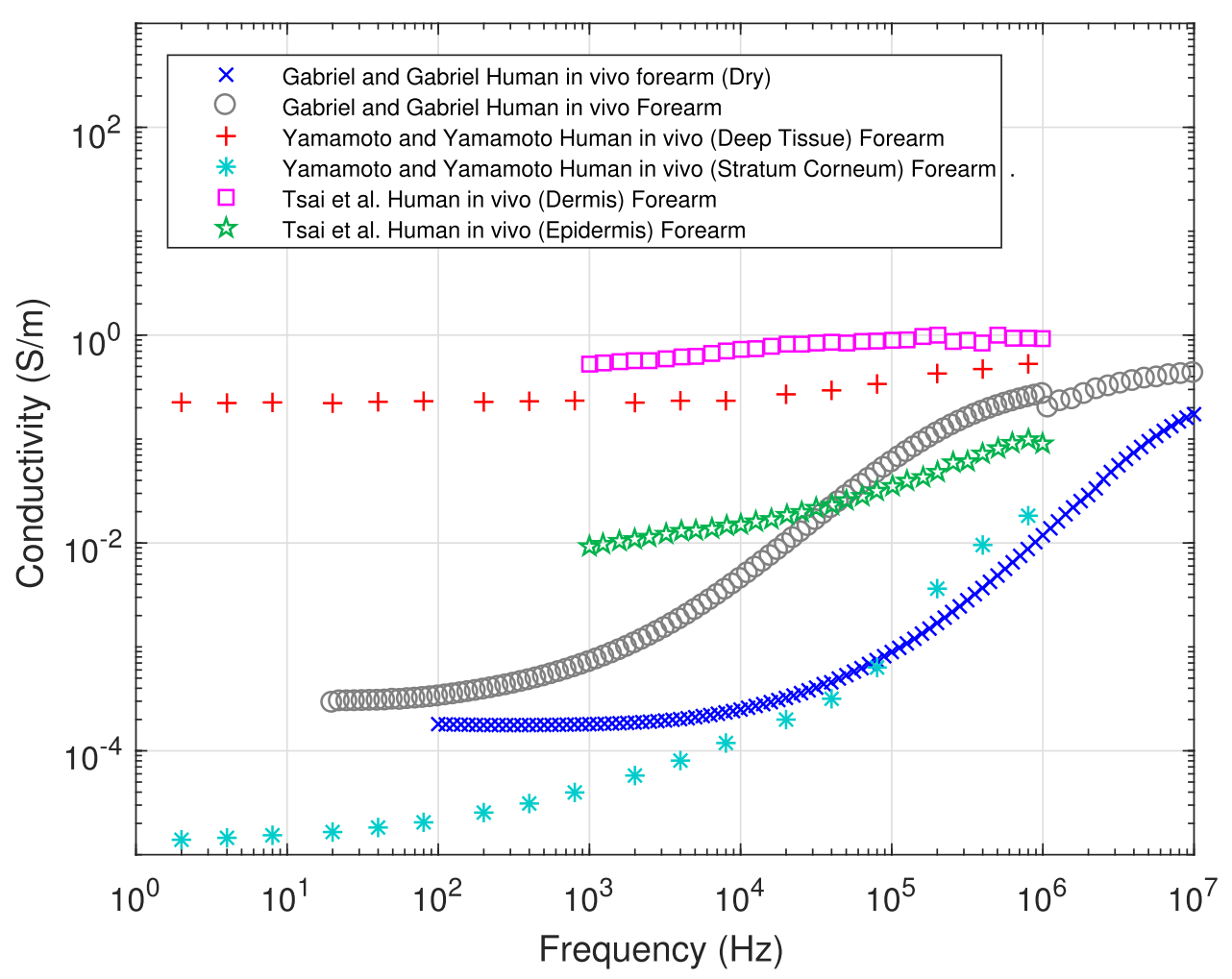

Figure 1. Skin conductivity.

\subsection{Measurement environment and tissue condition}

In general, it is not possible to take direct measurements of individual tissues in vivo. It is important that the excised tissue that measurements are taken from is in an environment that mimics that of being in situ in a live body as closely as possible (ex vivo).

It is also common for human autopsy materials to be used (Gabriel et al 1996a), especially for deep tissues and main organs. Once excised, it is important that the tissue be analysed as soon after removal/termination as possible, as cell death rapidly alters the internal structures of cells and organelles. It has been noted by Manwaring et al (2013) that during the euthanasia of piglets there was an immediate systematic decrease in global cerebral conductivity. The mean drop in conductivity before euthanasia and five minutes postmortem was measured as $12.6 \pm 13.2 \mathrm{mSm}^{-1}$ at $100 \mathrm{~Hz}$. For comparison, the increase in conductivity before and after blood was injected into a section of the brain of anaesthetised piglets was measured as $19.5 \pm 11.5 \mathrm{mSm}^{-1}$ (Manwaring et al 2013).

As very little data has been collected on the conductivity and permittivity for human tissues, mammalian tissue data is often utilised. The variation in a tissue's properties within a species may exceed the variation of that tissue's properties inter-species, depending on the tissue and the animal selected (Gabriel et al 1996). However, provided that a strong positive relationship may be shown over a limited frequency range, it can be assumed that non-human mammalian data can provide a valid approximation (Gabriel et al 1996, Gabriel et al 1996a, Gabriel et al 1996b).

\subsection{Head dielectric tissue properties}

The human head is constituted of several distinct layers of biological tissue; skin, muscle, skull, cranial meninges, cerebrospinal fluid (CSF), and brain white and grey matter. In this section, each tissue's conductivity and permittivity data sets that are available from the literature are tabulated (Figures 1-11) as well as discussed and their suitability analysed.

It may be seen in the data tabulated in Figures 1-11, that there are regions that contain too much data and thus lack clarity; in these instances, additional graphs displaying the dielectrical trends in greater detail are given in the online supplementary material available (online at stacks.iop.org/BPEX/7/025011/mmedia).

\subsubsection{Scalp}

There have been several studies on the electric properties on the human skin, but no frequency dependent studies on the scalp have been undertaken. Although the properties of the skin are known to vary across the different parts of the body, significant data was only found to be available from the skin of the forearm.

The dielectric properties of skin are divided into two categories; dry and wet. As it is normal practice to use a conductive gel to reduce the affect of the resistive boundary layer effects between electrodes and the skin, the 'wet' properties of the skin are considered in this paper. For the dielectric properties of 


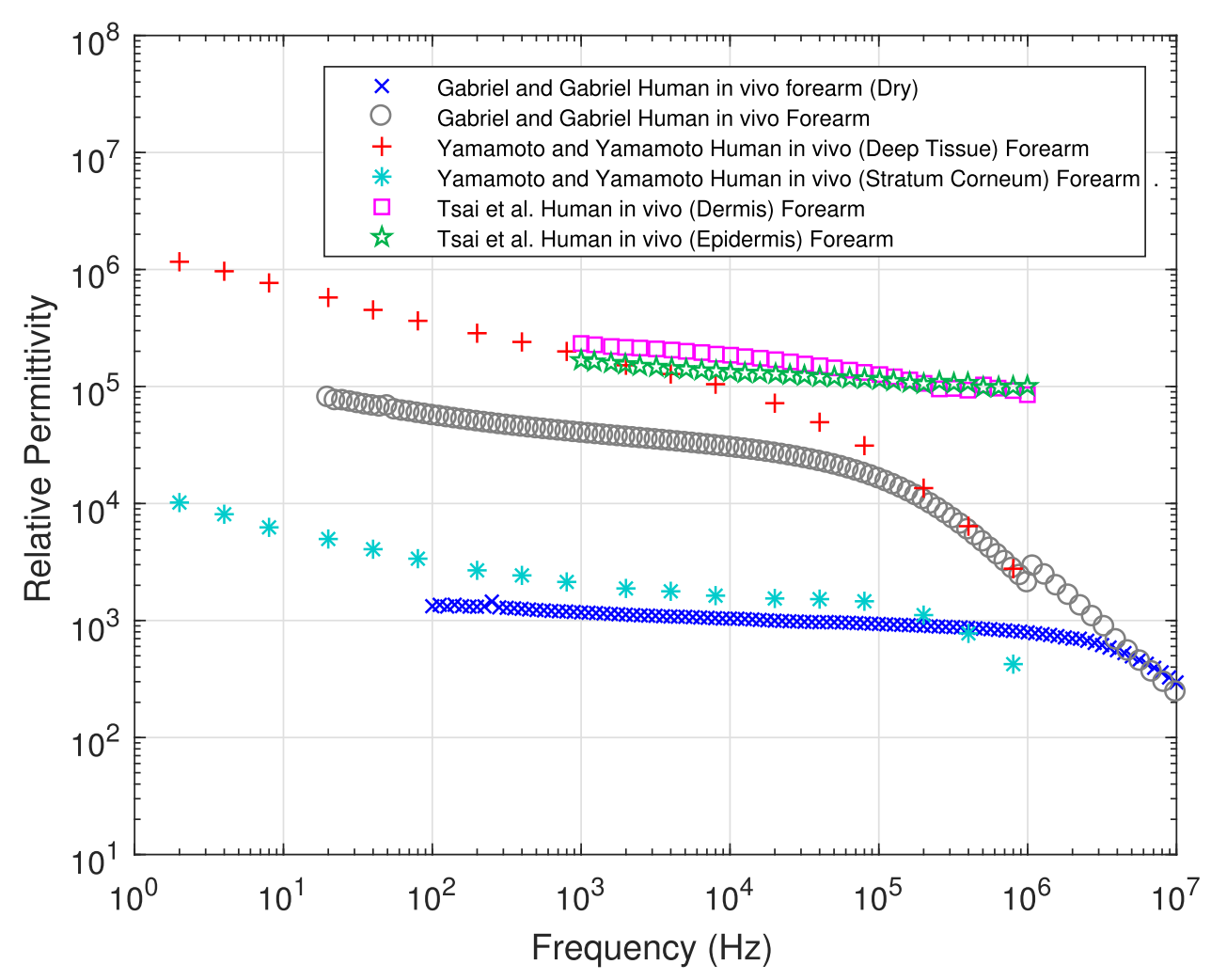

Figure 2. Skin relative permittivity.

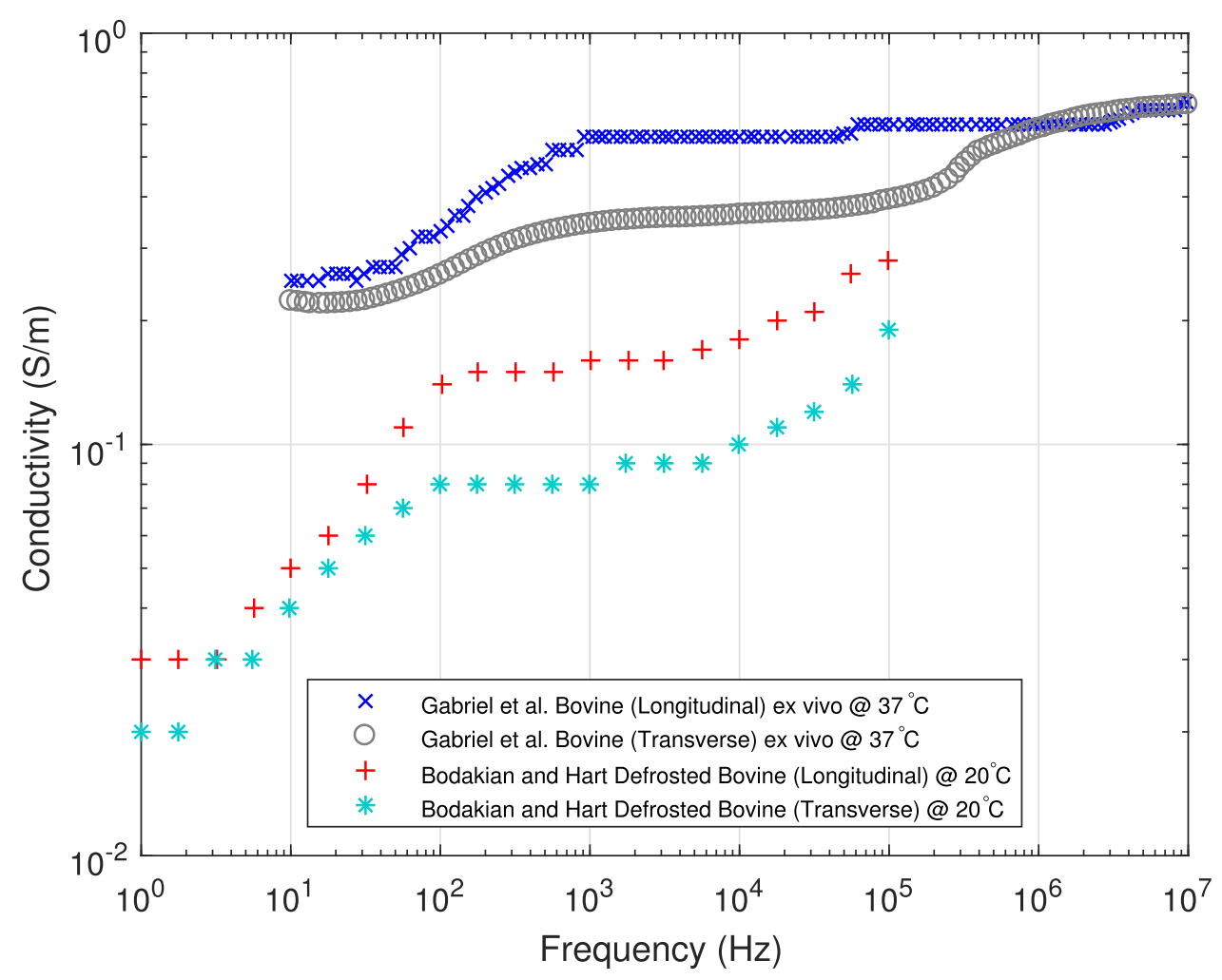

Figure 3. Muscle conductivity.

dry skin the following are recommended; (Grant et al 1988, Gabriel and Gabriel 1996, Tamyis et al 2005, Sasaki et al 2015).
Yamamoto and Yamamoto (1976) recorded the resistivity and permittivity of the skin of the forearm in vivo in the frequency range $2 \mathrm{~Hz}$ to $1 \mathrm{MHz}$. They measured the 


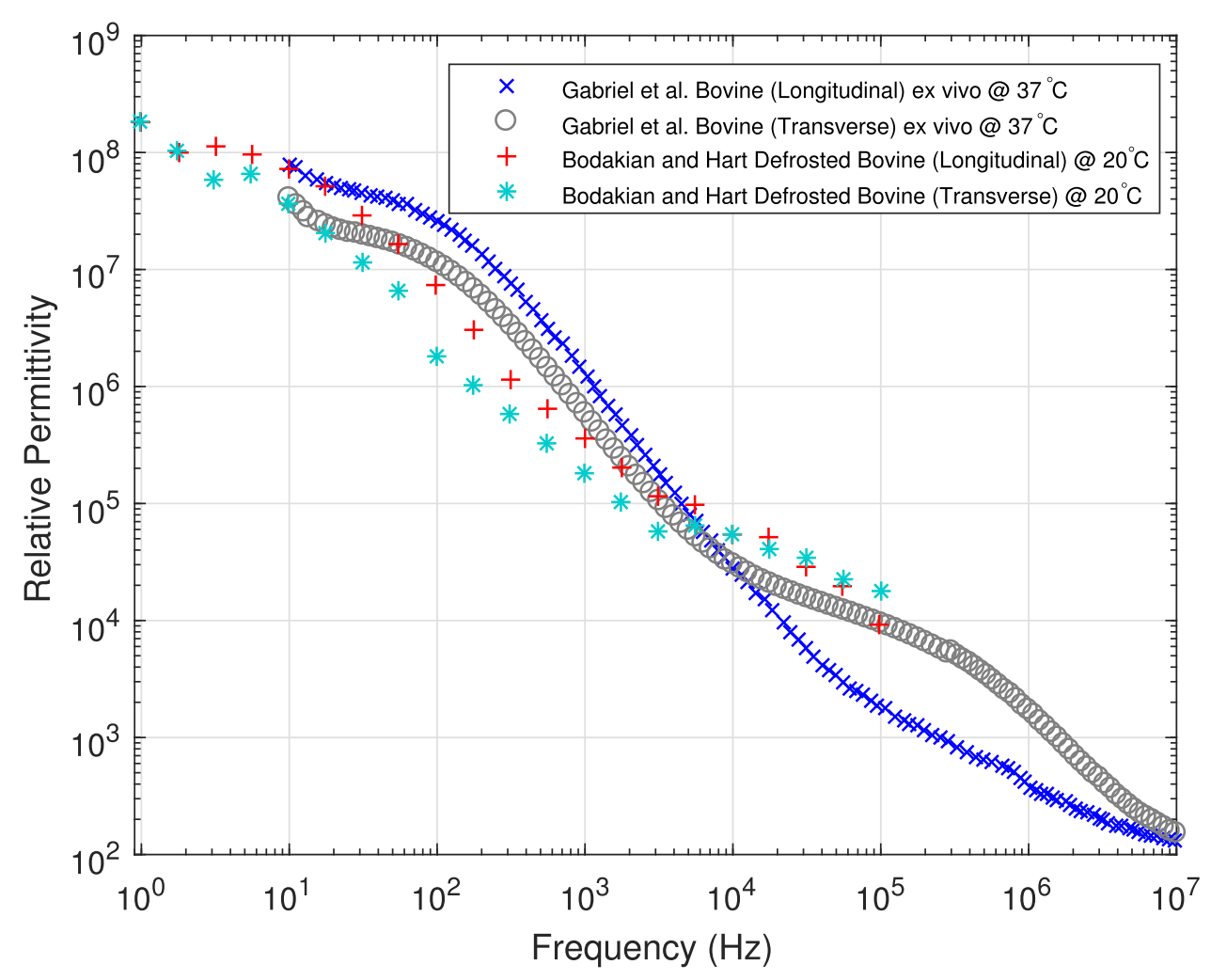

Figure 4. Muscle relative permittivity.

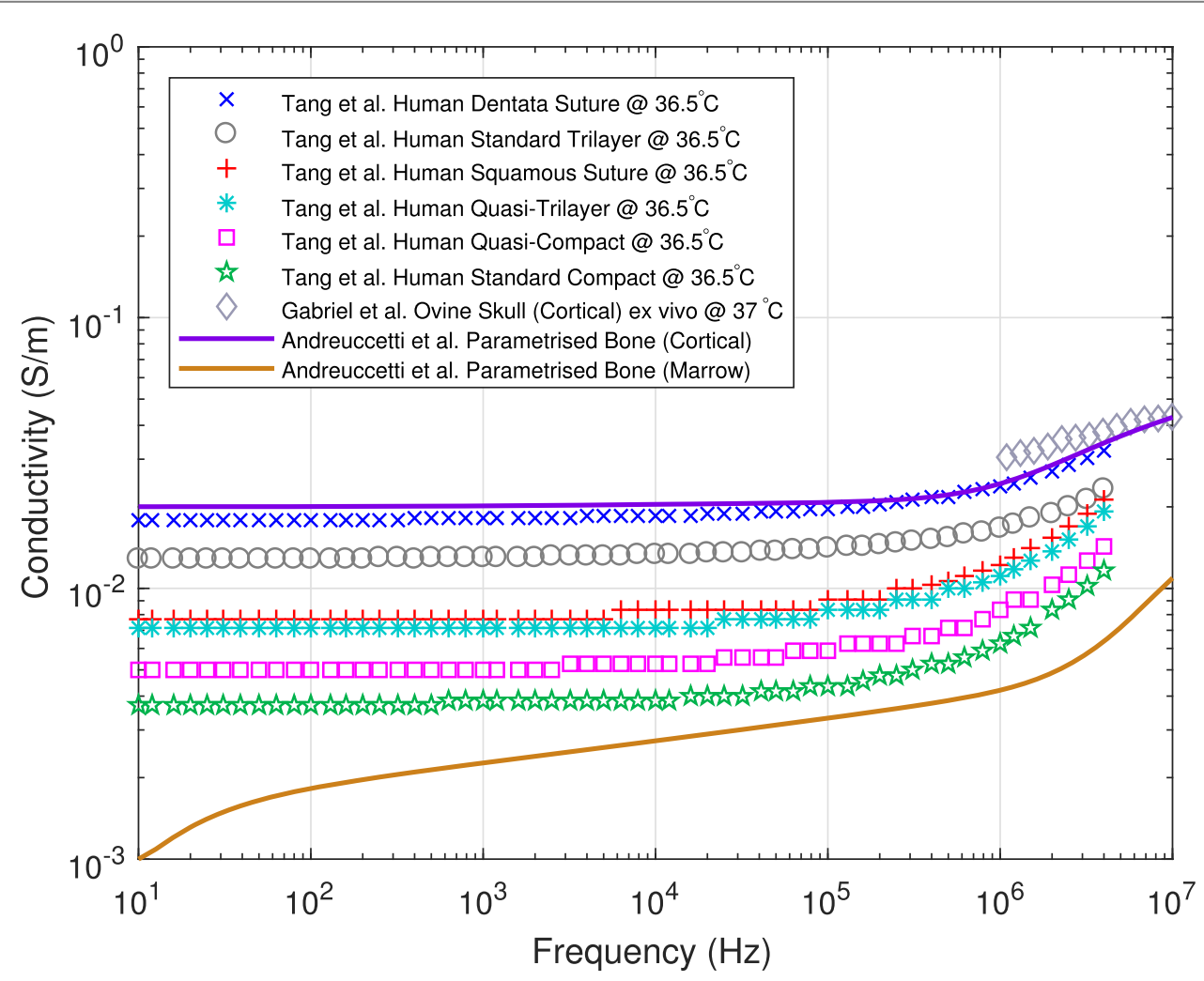

Figure 5. Skull conductivity.

electrical properties of the stratum corneum and deep tissue skin using the two terminal method and compensating for the effect of lead wire stray impedance and electrode polarisation. Tsai et al (2019) also measured the dielectric properties of different layers of human forearm skin in vivo over the frequency range of $1 \mathrm{kHz}$ to $1 \mathrm{MHz}$ 


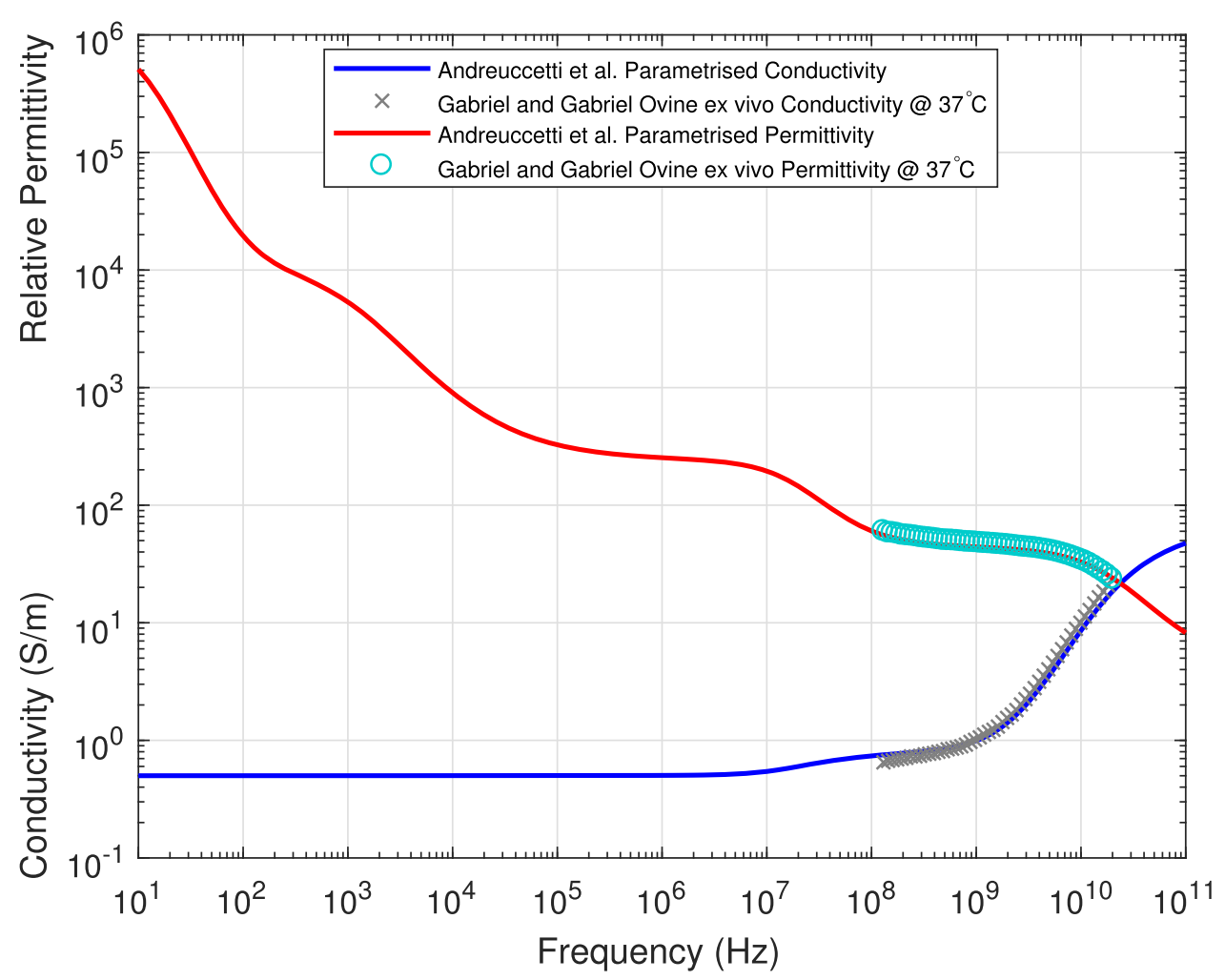

Figure 6. Dielectric properties of the dura mater.

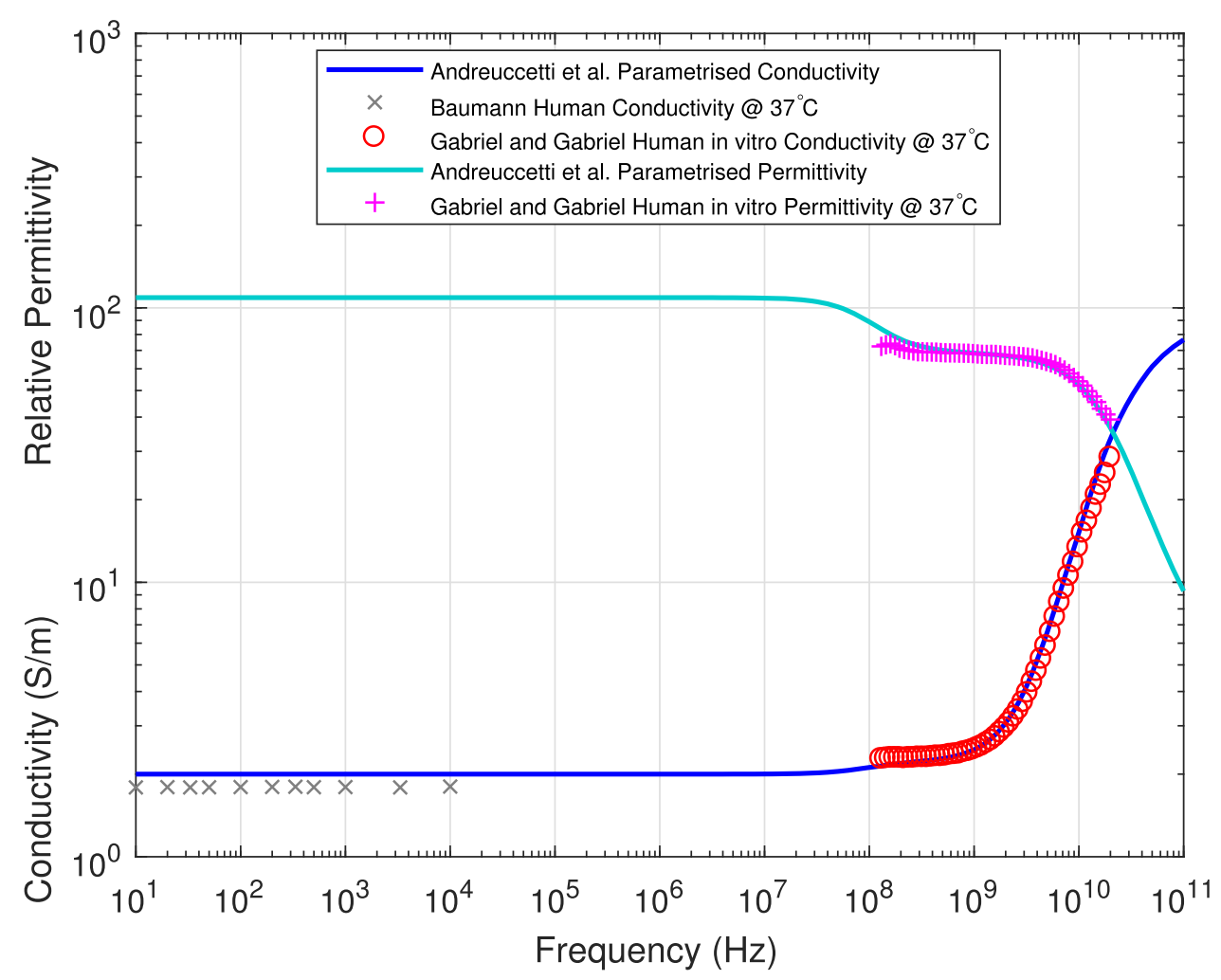

Figure 7. Dielectric properties of cerebrospinal fluid.

using the four-terminal method. They recorded measurements for the dermis and the epidermis by changing the effective current penetration depth of their recordings.
Gabriel and Gabriel (1996) conducted corrected two-terminal measurements on the skin of the forearm in vivo in both 'wet' and 'dry' conditions over a 


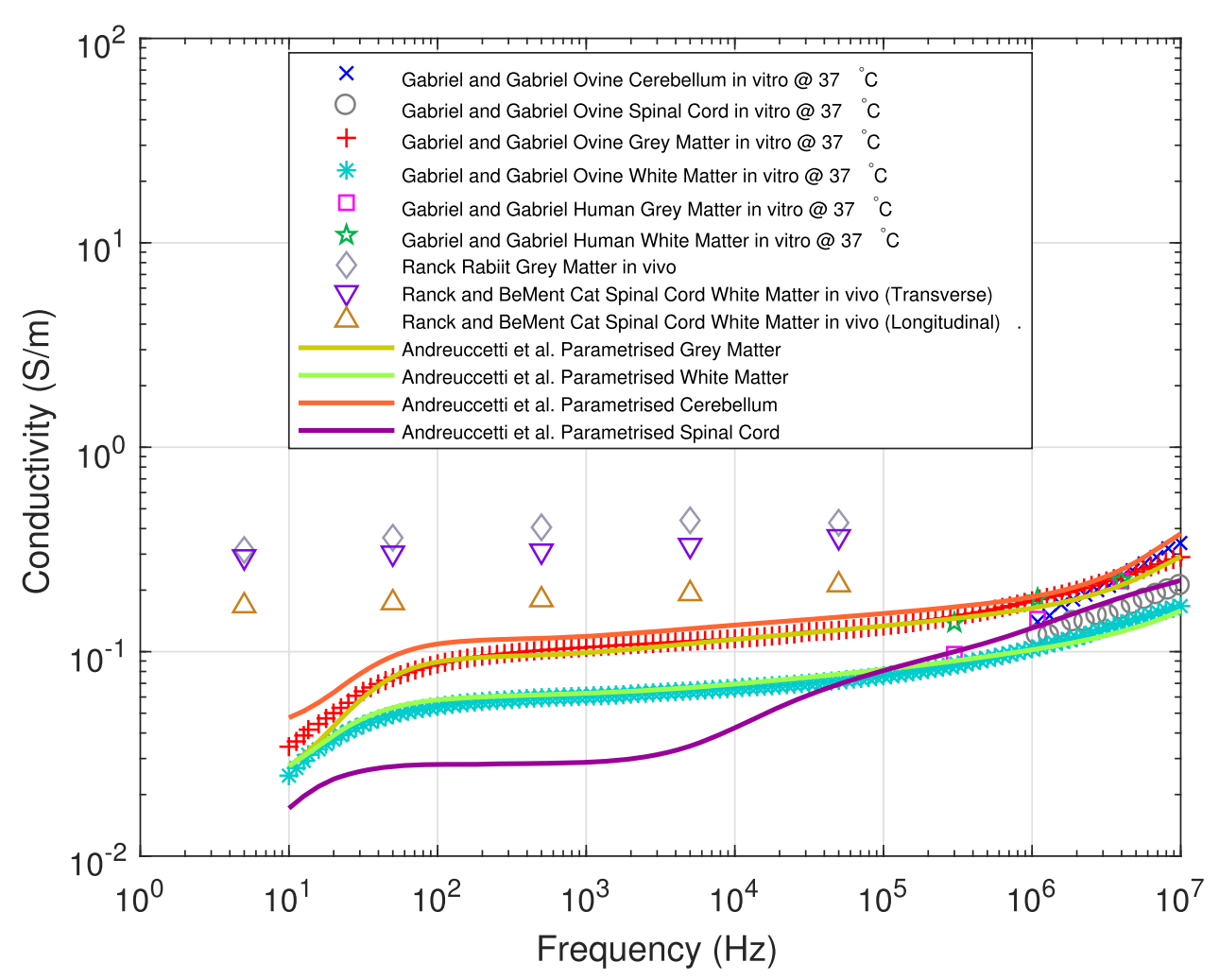

Figure 8. Conductivity of brain tissues.

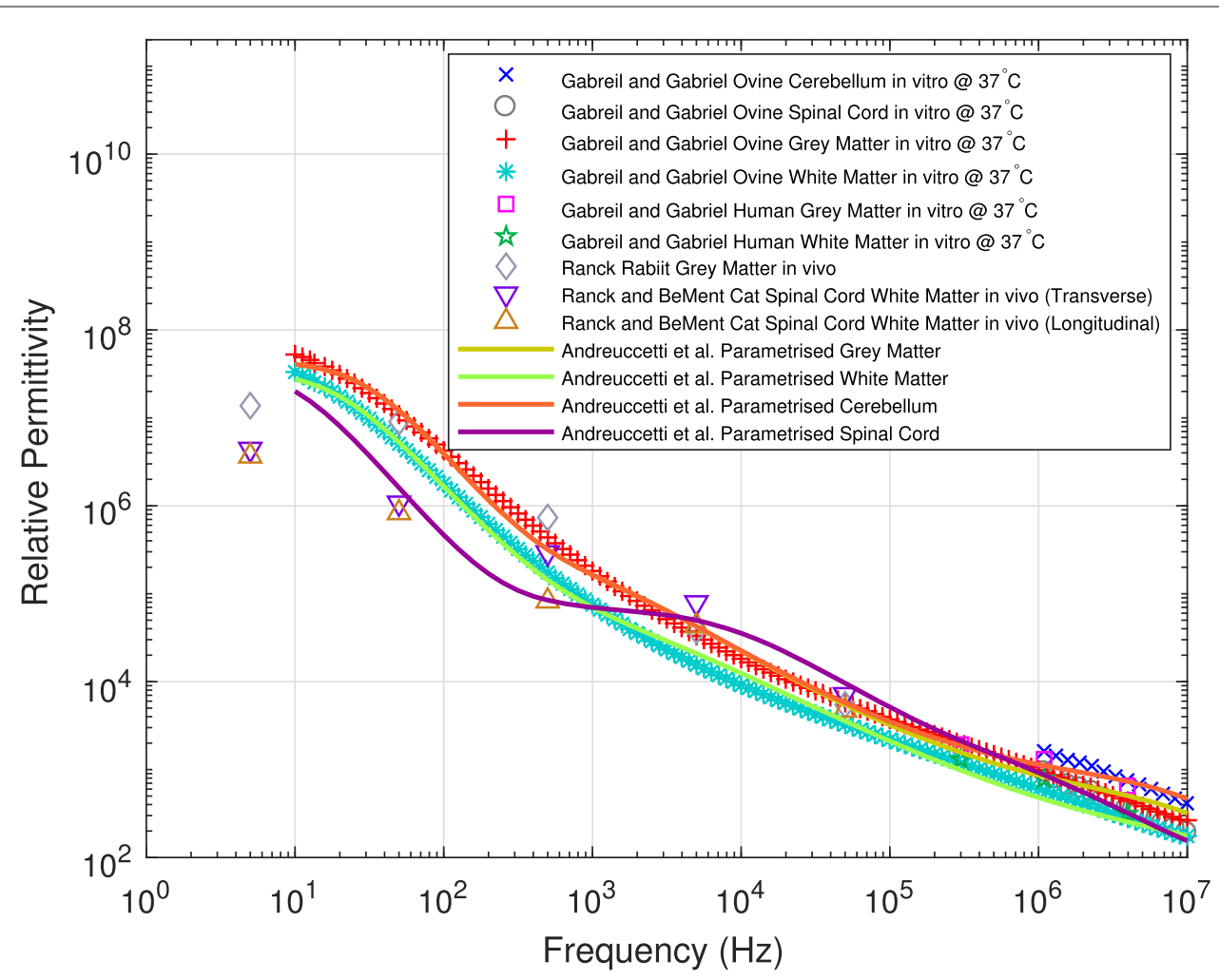

Figure 9. Relative permittivity of brain tissues.

wide frequency range from $10 \mathrm{~Hz}$ to $20 \mathrm{GHz}$. They corrected their results to account for lead inductance and electrode polarisation.
Figure 1 shows the conductivity of skin (and location when identified) extracted from Gabriel and Gabriel (1996) and the conductivity derived from the resistivity 


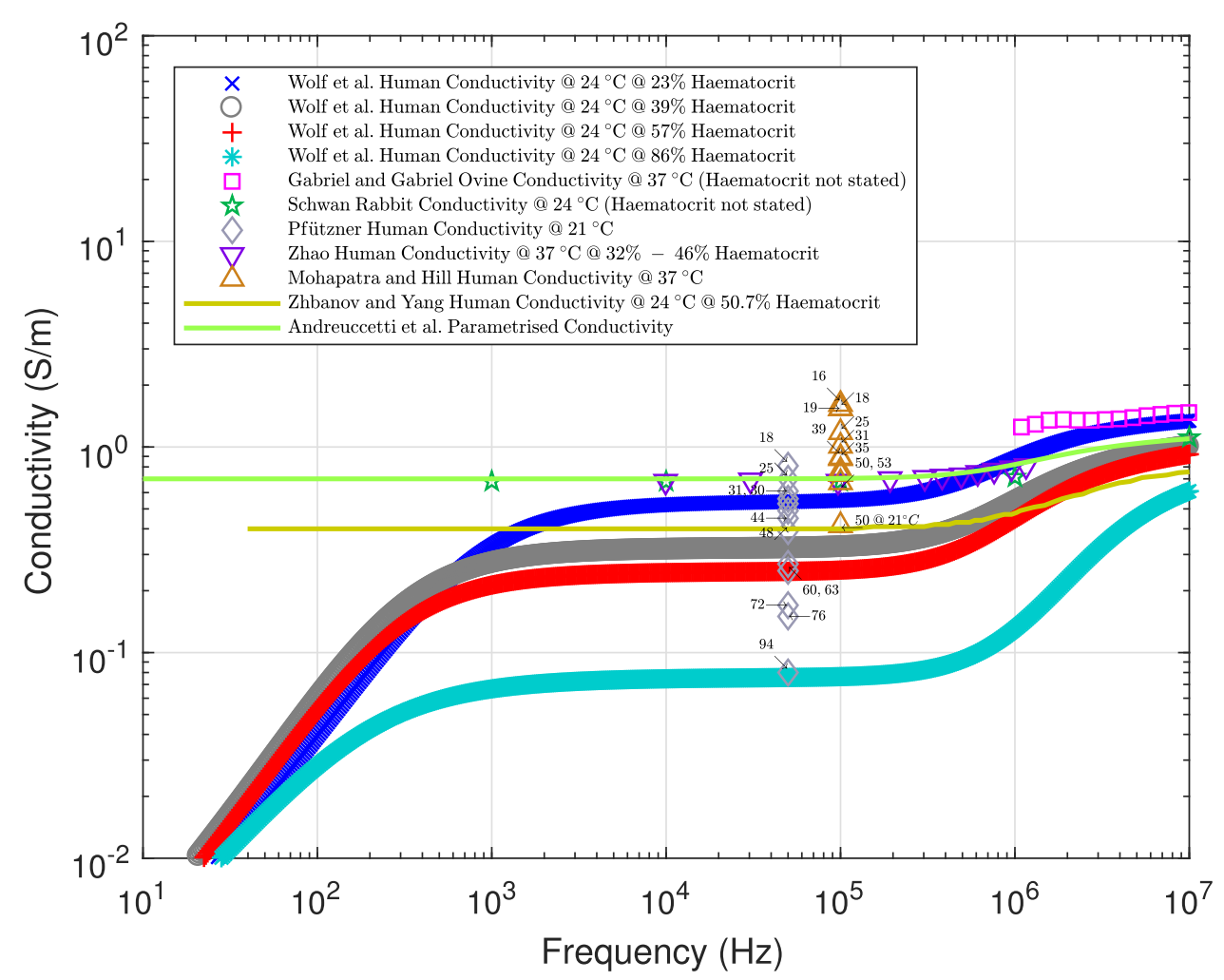

Figure 10. Conductivity of blood (numbers annotating Pftzner, and Mohapatra and Hill represent the HCT level in percentage).

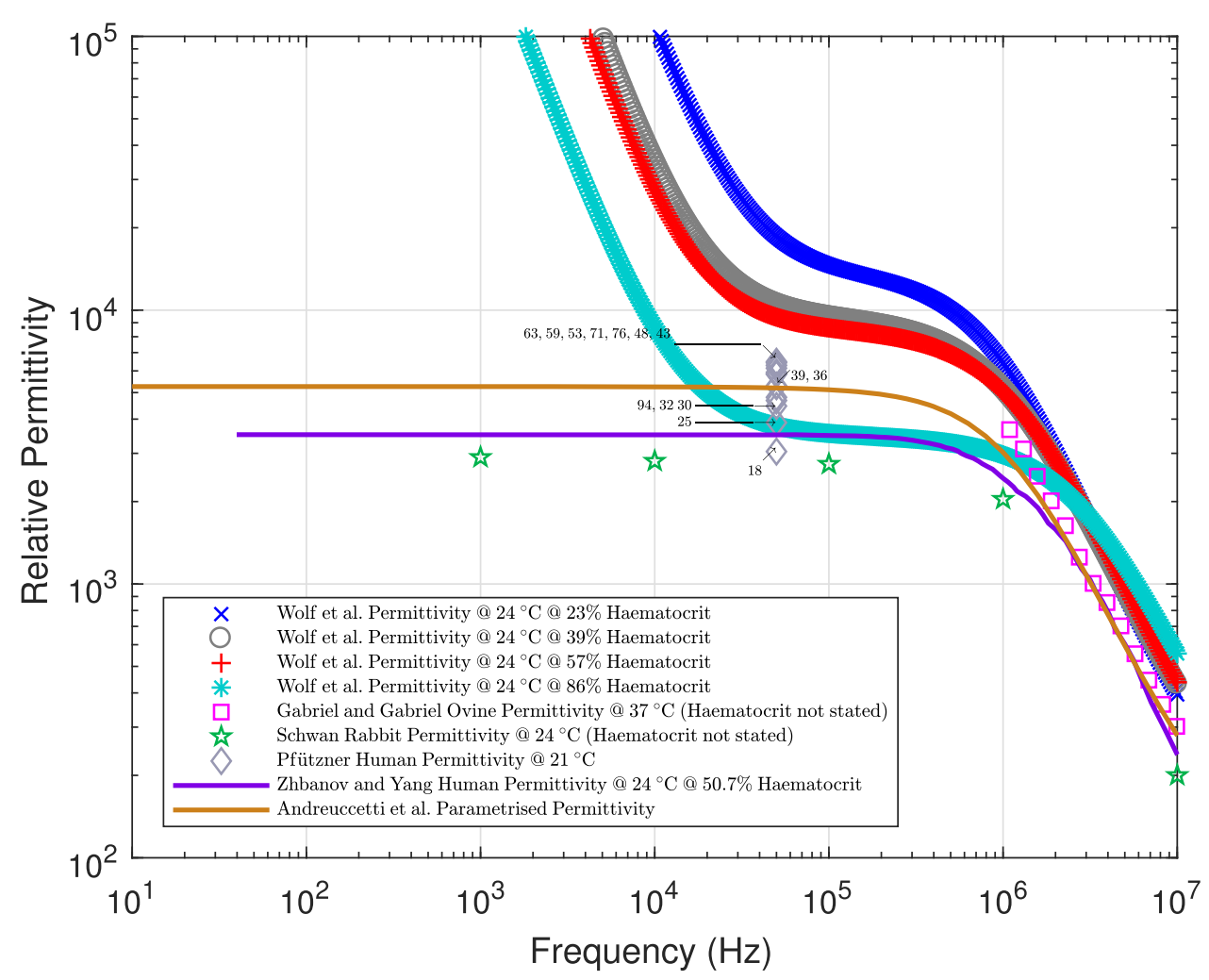

Figure 11. Relative permittivity of blood (numbers annotating Pftzner represent the HCT level in percentage).

measurements of Yamamoto and Yamamoto (1976) and Tsai et al (2019). Figure 2 shows the permittivity of skin extracted from Yamamoto and Yamamoto (1976), Tsai et al (2019), and Gabriel and Gabriel (1996).
From Figures 1 and 2 it can be seen that the Yamamoto and Yamamoto deep tissue skin measurements converge with Gabriel and Gabriel wet skin measurements at above $100 \mathrm{kHz}$ and diverge at lower 
frequencies. This is to be expected between sets of measurements that include/exclude the stratum corneum, because at high frequencies a tissue's capacitive effects (susceptivity) dominate its behaviour, negating the effects of the stratum corneum's conductivity and permittivity.

As Yamamoto and Yamamoto recorded only a single measurement for the skin (bar the stratum corneum) it is to be expected that Tsai et al individual dermis and epidermis measurements would differ in magnitude to Yamamoto and Yamamoto's deep skin measurements, but agree in their trend. This is true for the conductivity, but Tsai et al permittivity measurements describe a much shallower decrease above $10 \mathrm{kHz}$ then is shown by the other data sets.

\subsubsection{Muscle}

Muscle cells are much longer than they are thicker, giving muscle a very obvious anisotropic nature, longitudinally and transversely. There are several different muscle groups covering the skull overlaying one another and orientated in multiple directions. Muscle fibres, just like skin, are also expected to differ in their dielectric properties based on their location.

Gabriel et al (1996a) conducted corrected twoterminal measurements for the longitudinal and transverse conductivity and permittivity of bovine muscle in vitro at body temperature within two hours of death, over a frequency range of $10 \mathrm{~Hz}$ to $20 \mathrm{GHz}$. Bodakian and Hart (1994) examined the dielectric properties of longitudinal and transverse bovine muscles of defrosted samples at $20^{\circ} \mathrm{C}$ using the three terminal method.

Figures 3 and 4 show the dielectric properties of muscle tissue extracted from Bodakian and Hart (1994) and Gabriel et al (1996a).

It can be seen that the Gabriel et al measurements agree with the magnitude difference between the longitudinal and transverse muscle measurements of the defrosted bovine by Bodakian and Hart. The defrosted bovine muscle, Bodakian and Hart, is shown to be less conductive compared to fresh post mortem bovine muscle tissue by Gabriel et al. The non-agreement of results could be because the defrosted tissue was tested at $20^{\circ} \mathrm{C}$ instead of at body temperature $\left(37^{\circ} \mathrm{C}\right)$, and it is probable that the processes of freezing and defrosting the tissue physically altered its cellular structure, changing its dielectric behaviour.

\subsubsection{Skull}

The most detailed and comprehensive study of skull bone is provided by Tang et al (2008). Skull samples were excised during surgery from 48 live patients (10 female and 38 male), aged between $20-74$ years old. The resistivity of the samples were measured at $36.5^{\circ} \mathrm{C}$ over a frequency range of $1 \mathrm{~Hz}$ to $4 \mathrm{MHz}$. Measurements were taken for the six distinct skull sections of standard trilayer, quasi-trilayer, standard compact, quasi-compact, squamous suture, and dentate suture.
Gabriel et al (1994) conducted corrected twoterminal measurements on ex vivo ovine cortical skull bone at $37^{\circ} \mathrm{C}$ within two hours of death. The measurements were collected over a frequency range of $1 \mathrm{MHz}$ to $20 \mathrm{GHz}$. Andreuccetti et al (1997) developed parametrically modelled data sets based on data published by Gabriel and Gabriel (1996) and Gabriel et al (1996, 1996a, 1996b); parametrically modelled data sets were developed for generic cortical and marrow bone based on several independent studies of human, mammalian, in vivo and in vitro bone and skull bone. This data set spans over $10 \mathrm{~Hz}$ to $20 \mathrm{GHz}$.

Figure 5 shows the conductivity as a function of frequency for skull bone extracted from Tang et al (2008), Gabriel et al (1994), and Andreuccetti et al (1997). Tang et al skull bone and suture characterisation is recommended for reference as their measurements took into account the different types of skull bone cross-sections from a large sample of male and female patients, treating the skull as inhomogeneous.

\subsubsection{Cranial meninges}

The brain is enclosed by the cranial meninges which consist of three protective layers: the pia mater, the arachnoid mater and the dura mater. No dielectric data can be found analysing the pia mater, arachnoid, or the cranial meninges. Only one study by Gabriel and Gabriel (1996) was found to contain dielectric data for large mammalian dura mater. Gabriel and Gabriel measured ex vivo ovine dura at $37^{\circ} \mathrm{C}$ within two hours of death. The data was collected over a frequency range of $130 \mathrm{MHz}$ to $20 \mathrm{GHz}$; the data was then parametrically modelled and extrapolated over a frequency range of $10 \mathrm{~Hz}$ to $100 \mathrm{GHz}$ by Andreuccetti et al (1997).

Figure 6 displays the change in dielectric properties for dura mater with respect to frequency extracted from Gabriel and Gabriel (1996) and Andreuccetti et al (1997).

\subsubsection{Cerebrospinal fluid (CSF)}

CSF is an ionic fluid with a low density of cells, with $0-5$ cells $/ \mathrm{mm}^{3}$ normal for an adult (Martini 1998). As CSF is very conductive with no significant susceptivity (Baumann et al 1997), it can be assumed that in vitro measurements at body temperature should be representative of in vivo measurements.

Baumann et al (1997) recorded the conductivity of human CSF in vitro at $37^{\circ} \mathrm{C}$ using the four-terminal method between $10 \mathrm{~Hz}$ and $10 \mathrm{kHz}$. Gabriel and Gabriel (1996) measured in vitro human CSF at $37^{\circ} \mathrm{C}$ at between 24 to 48 hours postmortem. The measurements were collected over the frequency range of $130 \mathrm{MHz}$ to $20 \mathrm{GHz}$; Andreuccetti et al (1997) parametrically modelled and extrapolated Gabriel and Gabriel's measurements over the frequency range of $10 \mathrm{~Hz}$ to $100 \mathrm{GHz}$.

The dielectric properties of CSF extracted from Gabriel and Gabriel (1996), Baumann et al (1997) and 
Andreuccetti et al (1997) are shown graphically in Figure 7 . Below $10 \mathrm{kHz}$, there is approximately $11 \%$ difference between Baumann et al conductivity measurements, which have an average value of $1.79 \mathrm{~S} / \mathrm{m}$, and Andreuccetti et al conductivity values, which have an average value of $2.00 \mathrm{~S} / \mathrm{m}$ below $10 \mathrm{MHz}$. Baumann et al data was obtained using the four-terminal method for a frequency range of $10 \mathrm{~Hz}$ to $10 \mathrm{kHz}$, while Gabriel and Gabriel used the two-terminal method for their measurements that are the basis for Andreuccetti et al extrapolated data. Therefore, Baumann et al conductivity values should be considered to be more accurate.

\subsubsection{Brain tissue}

The adult brain is composed of a central region of white matter surrounded by a outer layer of grey matter. Grey matter is isotropic in its dielectric nature as opposed to the white matter which is constructed of bundles of nerve fibres that are very anisotropic. Therefore the orientation of the measuring electrodes has a significant effect on the measured dielectric property for white matter (Ranck and BeMent 1965).

Gabriel and Gabriel (1996) provide data with the broadest frequency range of measured white and grey matter of both human and large mammalian, and cerebellum and spinal cord of large mammalian. Gabriel and Gabriel measured the ex vivo ovine tissues at $37^{\circ} \mathrm{C}$ within two hours of death, and the ex vivo human tissue at $37^{\circ} \mathrm{C}$ at between 24 to 48 hours post mortem. Andreuccetti et al (1997) extrapolated data sets for the dielectric behaviour of the cerebellum and spinal cord from Gabriel and Gabriel's ovine measurements over the frequency range $10 \mathrm{~Hz}$ to $100 \mathrm{GHz}$. Andreuccetti et al also used Gabriel and Gabriel's ovine and human measurements and measurements from small mammalian subjects from other studies to create parametrised data sets for white and grey matter dielectric properties. The dielectric measurements of the aforementioned small mammals are in very strong agreement with the human and ovine results of Gabriel and Gabriel (1996). Ranck (1963) recorded the complex specific impedance of in vivo grey matter of two anaesthetised rabbits using the three-terminal method over the frequency range of $5 \mathrm{~Hz}$ to $50 \mathrm{kHz}$. Ranck and BeMent (1965) measured the complex specific impedance of in vivo white matter of the dorsal columns of five anaesthetised cats in both the longitudinal and transverse directions using the three-terminal method over the frequency range of $5 \mathrm{~Hz}$ to $50 \mathrm{kHz}$.

The conductivity and permittivity of brain tissues extracted from Gabriel and Gabriel (1996), Andreuccetti et al (1997), Ranck (1963), and Ranck and BeMent (1965) are shown in Figure 8 and Figure 9.

Figure 8 and Figure 9 also show that the Andreuccetti et al parametric approximations for conductivity and permittivity of white and grey matter, and spinal cord have good agreement with the ovine and human measurements from Gabriel and Gabriel. Ranck and
BeMent conductivity measurements of cat white matter in the longitudinal and transverse directions (Figure 8 and Figure 9) show the conductivity to be anisotropic and the permittivity to be isotropic in nature. The conductivity measurements of white matter in Figure 8 show that on average the conductivity is $73 \%$ lower in the longitudinal than the transverse direction. However, the permittivity measurements in Figure 9 show largely isotropic behaviour for the white matter. The Ranck and BeMent cat white matter permittivity measurements are in agreement with the trend of the Andreuccetti et al parametric approximation for human white matter.

\subsubsection{Blood}

The dielectric properties of blood vary dramatically based on its condition and composition. The dielectric properties depend upon the blood temperature, haematocrit (HCT) level (the percentage of red blood cells to blood by volume), flow rate, and whether the blood is whole or haemolysed (Hirsch et al 1950, Mohapatra and Hill Mohapatra and Hill 1975, Pfützner Pfützner 1984). The range of normal HCT levels for adults is from $40 \%$ to $54 \%$ for human males and $37 \%$ to $47 \%$ for females (Horesh 2006).

Zhao et al (1993) used the four-terminal method to measure the conductivity of human blood at body temperature of 24 patients with HCT levels over the range of $32 \%-46 \%$, over a frequency range of $10 \mathrm{kHz}$ to 1.2 MHz. Gabriel and Gabriel (1996) recorded the dielectric properties of ovine blood ex vivo at $37^{\circ} \mathrm{C}$ within two hours of death between $1.09 \mathrm{MHz}$ and $20 \mathrm{GHz}$. Andreuccetti et al (1997) extrapolated data sets for the dielectric behaviour of blood from Gabriel and Gabriel's ovine measurements and other mammalian tissue to produce calculated trends over the frequency range of $10 \mathrm{~Hz}$ to $100 \mathrm{GHz}$. Schwan (1963) measurements of rabbit blood is one of the studies used by Andreuccetti et al for defining the parametric model at low frequencies. The rabbit blood was measured in vitro at room temperature between $1 \mathrm{kHz}$ and $10 \mathrm{MHz}$, however, the HCT level of the blood was not stated by Schwan.

Mohapatra and Hill (1975) measured the resistivity of human blood in vitro at $100 \mathrm{kHz}$ using the twoterminal method with electrode polarisation corrections over a temperature range $22^{\circ} \mathrm{C}$ to $40^{\circ} \mathrm{C}$ and a HCT range $16 \%$ to $52.5 \%$. Pfützner (1984) recorded the dielectric properties of human and porcine blood in vitro at $50 \mathrm{kHz}$ and $21^{\circ} \mathrm{C}$ using the two-terminal method with raster electrodes over a HCT range of $94 \%$ to $18 \%$. Pftzner's work shows that as HCT level decreases admittivity (conductivity) increases and permittivity decreases, and that the admittivity of human and porcine blood are comparable at $50 \mathrm{kHz}$.

Wolf et al (2011) measured the dielectric properties of human blood from a single patient at $37^{\circ} \mathrm{C}$ over the frequency range of $1 \mathrm{~Hz}$ to $40 \mathrm{GHz}$ at $\mathrm{HCT}$ levels between $23 \%$ and $86 \%$. Wolf et al used the two- 
terminal method with a coaxial probe, but did not correct for electrode polarisation or compensate for stray capacitance. Zhbanov and Yang (2017) preformed dielectric testing on donated human blood that had been artificiality altered to a HCT of $50.7 \%$ at room temperature over a frequency range of $40 \mathrm{~Hz}$ to $110 \mathrm{MHz}$. The samples were measured with the two-terminal method using an impedance analyser with the results being corrected for electrode polarisation and stray impedance.

Figures 10 and 11 display the conductivity and permittivity of blood respectively extracted from the aforementioned papers. For each data set presented for the conductivity and permittivity in Figure 10 and Figure 11 respectively the blood HCT level is stated if given, and for the measurements of Mohapatra and Hill, and Pftzner the specific blood HCT of each data point is annotated as a percentage value (the percentage sign is not shown for clarity).

In Figure 10 Pfützner's $21^{\circ} \mathrm{C}$ measurements at $50 \mathrm{kHz}$ agree with the measurements of: Wolf et al at $24^{\circ} \mathrm{C}$ at $86 \%$ HCT with Pfützner's $94 \%$ HCT, Wolf et al at $24^{\circ} \mathrm{C}$ at $57 \%$ HCT with Pfützner's $63 \%$ HCT, Zhbanov and Yang at $24^{\circ} \mathrm{C}$ at $50.7 \%$ HCT and Mohapatra and Hill at $21^{\circ} \mathrm{C}$ at $50 \%$ HCT with Pfützner's $48 \% \mathrm{HCT}$, and Wolf et al at $24^{\circ} \mathrm{C}$ at $23 \% \mathrm{HCT}$ with Pfützner's $30 \%$ HCT. Mohapatra and Hill's measurement at $37^{\circ} \mathrm{C}$ at $50 \% \mathrm{HCT}$ at $100 \mathrm{kHz}$ agree with the measurements of Zhao at $37^{\circ} \mathrm{C}$ at between $32 \%$ to $46 \%$ HCT and Schwan's rabbit blood at $24^{\circ} \mathrm{C}$ and the parametrised data from Andreuccetti et al

Figure 11 shows that there is less agreement between the HCT of blood and its permittivity than its conductivity. Wolf et al $24^{\circ} \mathrm{C}$ measurements at $50 \mathrm{kHz}$ at $86 \% \mathrm{HCT}$ agree with Zhbanov and Yang's measurements at $24^{\circ} \mathrm{C}$ at $50.7 \% \mathrm{HCT}$ and Pfützner's $21^{\circ} \mathrm{C}$ measurement at between $25 \%$ and $18 \%$ HCT. The effect of not compensating for electrode polarisation using the two-terminal method is evident in both Figure 10 and Figure 11 in the Wolf et al data sets below $10 \mathrm{kHz}$ and $100 \mathrm{kHz}$ for the conductivity and permittivity measurements respectively, as opposed to the measurements of Zhbanov and Yang, Schwan, and Zhao that maintain a constant value at these low frequencies. The set of results that are deemed most representative of the dielectric behaviour of human blood at body temperature $\left(37^{\circ} \mathrm{C}\right), 40 \%-50 \% \mathrm{HCT}$, and taking into account electrode polarisation is the parametric data sets by Andreuccetti et al Their results agree with the general magnitude and trend of the data sets that compensate for electrode polarisation at lower frequencies at $37^{\circ} \mathrm{C}$ in both Figure 10 and Figure 11, as discussed in the text above.

The normal range of HCT levels for human adults is $37 \%$ to $52 \%$ (Horesh 2006). The corresponding conductivity values are $0.89 \mathrm{Sm}^{-1}$ and $0.68 \mathrm{Sm}^{-1}$ respectively; these are extrapolates from Mohapatra and Hill's results taken at $37^{\circ} \mathrm{C}$. This gives an expected percentage change of $75 \%$ between the HCT levels of
$38.5 \%$ and $52.5 \%$ at $37^{\circ} \mathrm{C}$ at frequencies below $1 \mathrm{MHz}$ for the conductivity of human blood.

\section{Assessment of the mathematical assumptions for EIT}

The governing equation of EIT is derived from Maxwell's equations. In order to derive it, several assumptions are made about the cellular structure and dielectric properties of all the tissues. Two of Maxwell's equations that are used in the derivation of the governing equation are Faraday's law of induction and Coulomb's law given below in (3) and (4) respectively; where $\mathbf{E}$ is the electric field, $\mathbf{B}$ is the magnetic flux, $t$ is time, $\mathbf{H}$ is the magnetic field, $\mathbf{D}$ is the electric displacement, and $\mathbf{J}$ is the electric current density:

$$
\begin{gathered}
\nabla \times \mathbf{E}=-\frac{\partial \mathbf{B}}{\partial t}, \\
\nabla \times \mathbf{H}=\frac{\partial \mathbf{D}}{\partial t}+\mathbf{J} .
\end{gathered}
$$

Using the current assumptions that for each biological tissue:

(i) The tissue is a linear isotropic medium

(ii) The internal current source density is negligible at the induced measurement frequency, $\mathbf{J}_{\mathrm{s}} \approx 0$

(iii) The tissue is a non-dispersive medium and that magnetic effects are negligible, $\omega \mu \mathbf{H} \approx 0$

(iv) The tissue is a conductive medium (i.e. $\mathbf{J}_{\mathrm{c}}=\sigma \mathbf{E}$ ), and the capacitive effects $\omega \epsilon$ are negligible

(3) and (4) may be expanded to Maxwell's time harmonic equations, (5) and (6) respectively; where $j$ is the unit imaginary number, $\omega$ is the angular velocity, $\mu$ is the magnetic permeability, and $\mathbf{J}_{\mathbf{c}}$ is the conduction current density:

$$
\begin{gathered}
\nabla \times \mathbf{E}=-\mathbf{j} \omega \mu \mathbf{H} \approx 0, \\
\nabla \times \mathbf{H}=\mathbf{j} \omega \epsilon \mathbf{E}+\mathbf{J}_{\mathrm{c}}=(\sigma+\mathbf{j} \omega \epsilon) \mathbf{E} \approx \sigma \mathbf{E} .
\end{gathered}
$$

As the curl of $\mathbf{E}$ tends to zero in (5), $\mathbf{E}$ is equivalent to a gradient of a scalar, $\mathbf{E} \equiv-\nabla \phi$, where the scalar $\phi$ is the electric potential. Substituting for $\mathbf{E}$ in (6) and taking the divergent of both sides reduces (6) to a single second order elliptic partial differential equation, (7), noting that the divergence of a curl of a vector is equal to zero (i.e. $\nabla \cdot(\nabla \times \mathbf{H}) \equiv 0)$. Equation (7) is often referred to as the governing equation of EIT and allows for the calculation of the electric potential $\phi$ once the boundary conditions are defined.

$$
\nabla \cdot(\sigma \nabla \phi)=0 .
$$

By using the governing equation (7), the user implicitly assumes that the above assumptions (i) to (iv) are valid, which is not always true for every biological tissue at every frequency. Therefore, it is important to define the validity of the assumptions in 
relation to the tissue(s) being investigated and the technique applied (e.g. the frequency range used). The validity of each assumption is discussed below for human head tissues.

\subsection{Linear isotropic medium assumption}

This assumption is not true for all of the tissues that constitute the human head. Scalp, muscle, skull, and white matter are known to be anisotropic. The anisotropic nature of muscle has been relatively well documented, but for scalp, skull, and white matter less information is available. It is unclear how the anisotropic nature of the scalp and skull would affect the propagation of electrical current. However for white matter, which is the central internal tissue in the head, it can be assumed that its anisotropy is equally orientated, and therefore could be modelled globally as an isotropic tissue (Horesh 2006). Therefore, the assumption that human head tissues are linear isotropic mediums is not true for the scalp and skull tissues.

\subsection{Internal current source density assumption}

The electric current density is influenced by two factors, the conduction current density $\mathbf{J}_{\mathrm{c}}$ and the internal source current density $\mathbf{J}_{\mathrm{s}}$. The total electrical current density $\mathrm{J}$ is given as:

$$
\mathbf{J}=\mathbf{J}_{\mathrm{c}}+\mathbf{J}_{\mathrm{s}} \text {. }
$$

The activity of brain waves above $200 \mathrm{~Hz}$ are linked to the onset or presence of seizures and spasms (Hughes 2008). Therefore, externally injected current should be limited to above $200 \mathrm{~Hz}$ so not to be contaminated by internal sources during normal brain function. Thus, in EIT applications it is correctly assumed that $\mathbf{J}_{\mathrm{s}} \rightarrow 0$ at the induced measurement frequency $(>200 \mathrm{~Hz})$.

\subsection{Assumption of negligible magnetic effects}

It is often assumed that for biomaterial $\omega \mu \mathbf{H} \approx 0$. The quasi-static approximation states that this is valid only if (Nunez and Srinivasan 2006):

$$
\frac{\omega \mu \sqrt{\sigma^{2}+(\omega \epsilon)^{2}}}{K^{2}} \ll 1 .
$$

where $K$ is the magnitude of the wavenumber vector. The left hand side (LHS) of (9) is defined as the ratio between magnetic induction and the conductive effects. As biological tissues are non-metallic the permeability of each tissue can be assumed to be the permeability of free space, $\mu \approx \mu_{0}=1.257 \times$ $10^{-6} \mathrm{Hm}^{-1}$.

Assuming that the tissues are non-dispersive lossless mediums, the magnitude of the wavenumber vector is calculated as:

$$
K=\frac{2 \pi}{\lambda} .
$$

where $\lambda$ is the characteristic spatial wavelength. Thus, the ratio in (9) is directly proportional to $\lambda^{2}$. Therefore, a large value of $\lambda$ will result in a conservative approximation of the ratio in (9) with respect to the upper limit of 1 (Nunez and Srinivasan 2006).

Bushby et al (1992) recorded the heights and head diameters of 354 white adults, finding that the head diameter is proportional to height. The 97 th percentile of head diameter for men with a height of $200 \mathrm{~cm}$ was found to be $62.4 \mathrm{~cm}$. As an overestimation, a head diameter of $65 \mathrm{~cm}$ has been used to calculate a characteristic spatial wavelength of $0.207 \mathrm{~m}$, resulting in a wavenumber vector magnitude of $30.4 \mathrm{~m}^{-1}$ (Nunez and Srinivasan 2006).

Using the above value of $K$ and the dielectric behaviour of each tissue described in Section 2 (using generic bone data instead of skull bones due to a lack of skull permittivity data), the ratio in (9) is plotted against frequency in Figure 12.

It can be seen in Figure 12 that the ratio in (9) of all the tissues remains below 0.01 up to $600 \mathrm{kHz}, 0.017 \mathrm{up}$ to $1 \mathrm{MHz}$, and 0.1 up to $6 \mathrm{MHz}$. Therefore, the assumption that the magnetic induction is negligible is a very good approximation at frequencies less than $1 \mathrm{MHz}$, with the assumption becoming less valid at higher frequencies.

\subsection{Assumption of negligible capacitive effects}

It is often assumed that the capacitive effects $(\omega \in \mathbf{E})$ are negligible compared to the conductive effects within biological tissues. This assumption requires that a tissue's admittivity, $\gamma$, is equivalent to its conductivity, i.e. $\gamma \approx \sigma$. Admittivity is the combined effects of the real conductivity and the imaginary susceptivity, given as:

$$
\gamma=\sigma+\mathrm{j} \omega \epsilon
$$

If it is assumed that admittivity is equivalent to conductivity, by dividing (11) by $\sigma$ it is clear that the ratio of susceptivity and conductivity must be much less than one for the quasi-static approximation of negligible capacitive effects to be valid.

$$
\frac{\omega \epsilon}{\sigma} \ll 1
$$

Figure 13 displays the ratio in (12) applied to the tissues described previously in this paper (as used in assumption 3 above).

Figure 13 shows that bar the stratum corneum the ratio for all the tissues remains below 1 for frequencies less than $10 \mathrm{MHz}$, with the minimum ratio of 0.14 at $1 \mathrm{kHz}$. Figure 13 also shows that the assumption of negligible capacitive effects is valid for some tissues, but not for others, specifically not for brain tissue. For example, the minimum ratio for brain tissues is that of the white matter which is 0.062 ; while the ratio for CSF, dura mater, blood, bone (cortical), and deep tissue skin is below 0.01 at frequencies less than $3.2 \mathrm{MHz}$, $320 \mathrm{kHz}, 25 \mathrm{kHz}, 3.2 \mathrm{kHz}$ and $130 \mathrm{~Hz}$ respectively. Therefore, it is questionable, specifically for head tissues, as to the validity of the assumption that the effect 


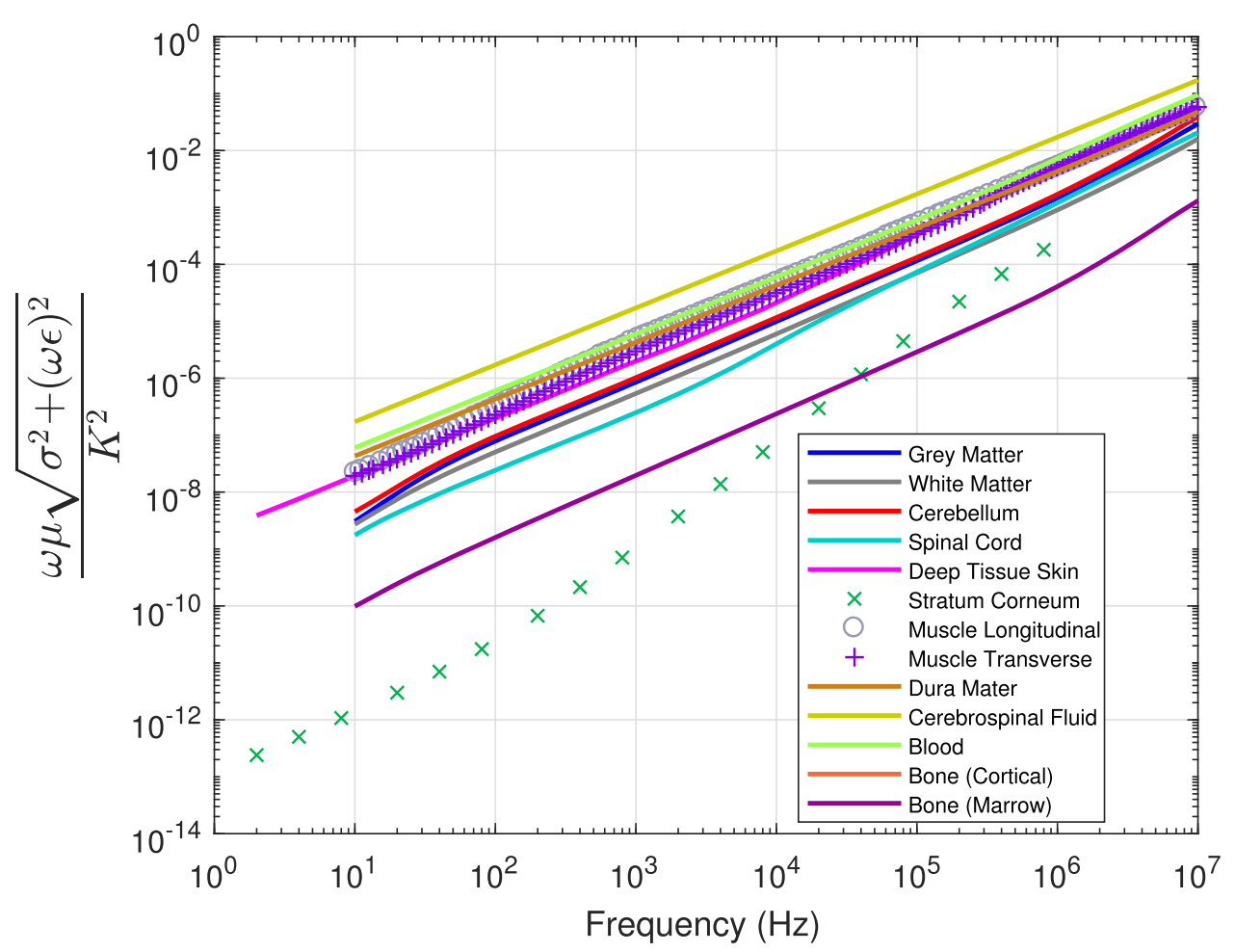

Figure 12. Evaluation of the magnetic quasi-static approximation.

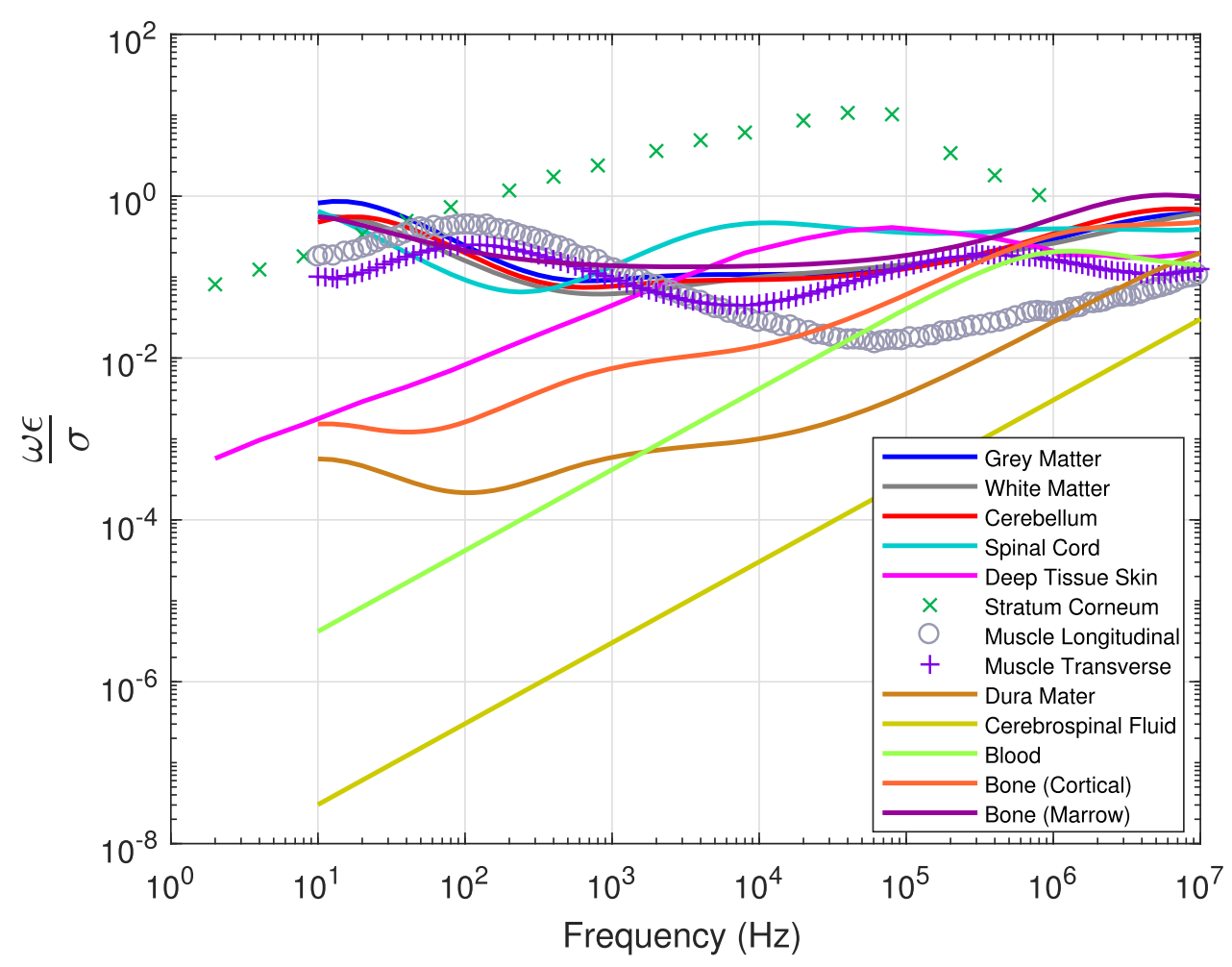

Figure 13. Evaluation of the capacitive quasi-static approximation.

of capacitance is negligible, as across the given frequency spectrum the majority of the tissues, at any given frequency, cannot be described as significantly less than 1.

\section{Discussion and conclusions}

A study of the dielectric properties of human head tissues has been undertaken to investigate the validity 
of the key mathematical assumptions used in EIT. Accurate images of the conductivity map generated from EIT relies on accurate data to describe the dielectric behaviour of the materials under analysis. Thus, without a complete understanding of the effect the electrical responses of the human head tissues on the assumptions made for EIT, there is a potential for significant errors to occur. This is of increasing concern with regard to medical applications as falsenegative or false-positive results my have severe consequences.

The most relevant dielectric tissue data for tissues constituting the human head have been evaluated and critiqued for their suitability. The dielectric data have been used to assess the validity of the mathematical assumptions of EIT in terms of their suitability for human head imaging.

Andreuccetti et al (1997) maintain an online database of mathematically modelled dielectric properties of human tissues based on measurements and models of human and mammalian tissues by Gabriel and Gabriel (1996), Gabriel et al (1996, 1996a, 1996b), and others. This database gives very good approximations of tissue data and trends in general, but does not give data for local variations, such as scalp and flat muscle, or differentiation between the white and grey matters of different regions of the brain. Regions of the same tissue across the body are known to differ in their structural make-up depending on their location and, therefore, their dielectric behaviours are expected to differ also. Thus, Andreuccetti et al calculated data sets should be used with caution.

The main recommendations that describe the dielectric behaviour of each tissue are summarised below. In addition, graphical representation of the recommended data sets of the head tissues are supplied in the supplementary material.

- The scalp can be represented by forearm human skin measurements by Gabriel and Gabriel (1996) above $1 \mathrm{MHz}$, and below $1 \mathrm{MHz}$ as a single entity by the forearm deep tissue skin measurements by Yamamoto and Yamamoto (1976) and as the dermis and epidermis separately between $1 \mathrm{kHz}$ and $1 \mathrm{MHz}$ by Tsai et al (2019).

- Muscle, transverse and longitudinal, can be represented by the bovine measurements by Gabriel et al (1996a)

- The skull conductivity can be represented by the human measurements of Tang et al (2008) below $4 \mathrm{MHz}$, which take into account the inhomogeneity of the skull, and the ovine cortical skull measurements by Gabriel et al (1994) above $4 \mathrm{MHz}$.

- The dura mater, CSF, grey matter, white matter, cerebellum, spinal cord, and blood at around 50\%$52 \%$ HCT can be represented by the calculated tissue behaviours by Andreuccetti et al (1997).
The tissues analysed in this paper indicate that the assumption that internal current source density is negligible at the induced measurement frequency, and the assumption that magnetic effects are negligible, are valid to an error of $1.7 \%$ for human head tissues over the frequency range of $200 \mathrm{~Hz}$ to $1 \mathrm{MHz}$. The assumptions of negligible capacitive effects and isotropic tissues do not hold true for all human head tissues without introducing significant error. The scalp, muscle, skull, and white matter are known to be anisotropic. Abascal (2007) noted a 50\% error in boundary voltages between two computer simulations, where one simulation accounted for the estimated anisotropy of the brain, skull and scalp, and the other did not.

EIT in its current form cannot be expected to give accurate results for the application of human head imaging without considering capacitive effects and obtaining a greater understanding of the anisotropy of the tissues. However, if complex admittivity was utilised in lieu of just the real part (conductivity) in defining the governing equation, (7), EIT could be expected to give valid results up to $1 \mathrm{MHz}$ depending on the magnitude of the effect that anisotropy has on the scalp, muscle, and skull tissues.

In order to mitigate the effect of the errors caused by the assumption that human head biological tissues are homogeneous and isotropic, more measurements of the skin, scalp, muscle, and white matter are required to be undertaken to increase the knowledge of how these tissues behave over a range of frequencies. This is also true of blood; it is necessary to understand how variations of blood HCT level affect the conductivity and permittivity in frequencies above the steady state condition $(<100 \mathrm{kHz})$. Research should also be conducted on the possibility of using admittivity to define the governing equation instead of conductivity to reduce the errors incurred by using the false assumption of negligible capacitive effects on human head tissues.

\section{Data availability statement}

The data that support the findings of this study are available upon reasonable request from the authors.

\section{ORCID iDs}

Toby Williams (ib https:// orcid.org/0000-00027162-2507

Massimiliano Zecca (iD https://orcid.org/0000-00034741-4334

\section{References}

Abascal J F P 2007 Improvements in reconstruction algorithms for electrical impedance tomography of brain function University of London

Andreuccetti D, Fossi R and Petrucci C 1997 "An internet resource for the calculation of the dielectric properties of body tissues in the frequency range $10 \mathrm{~Hz}-100 \mathrm{GHz}$ ". IFAC-CNR, Florence (Italy), 1997. Based on data published by C. Gabriel et al. in 1996. [Online]. Available: http://niremf.ifac.cnr.it/ tissprop/ 
Baumann S B, Wozny D R, Kelly S K and Meno F M 1997 The electrical conductivity of human cerebrospinal fluid at body temperature IEEE Trans. Biomed. Eng. 44 220-3

Bodakian B and Hart F X 1994 The dielectric properties of meat IEEE Trans. Dielectr. Electr. Insul. 1 181-7

Bushby K M D, Cole T, Matthews J N S and Goodship J A 1992 Centiles for adult head circumference Archives of Disease in Childhood 67 1286-7

Gabriel C, Chan T Y A and Grant E H 1994 Admittance models for open ended coaxial probes and their place in dielectric spectroscopy Phys. Med. Biol.392183-200

Gabriel C and Gabriel S 1996 Compilation of the dielectric properties of body tissues at RF and microwave frequencies http: / www. dtic.mil/dtic/tr/fulltext/u2/a305826.pdf

Gabriel C, Gabriel S and Corthout E 1996 The dielectric properties of biological tissues: I. Literature survey Phys. Med. Biol. 41 2231-49

Gabriel S, Lau R W and Gabriel C 1996a The dielectric properties of biological tissues: II.Measurements in the frequency range 10 Hz to $20 \mathrm{GHz}$ Phys. Med. Biol. 41 2251-69

Gabriel S, Lau R W and Gabriel C 1996b The dielectric properties of biological tissues: III. Parametric models for the dielectric spectrum of tissues Phys. Med. Biol. 41 2271-93

Grant J P, Clarke R N, Symm G T and Spyrou N M 1988 In vivo dielectric properties of human skin from $50 \mathrm{MHz}$ to $2.0 \mathrm{GHz}$ Phys. Med. Biol. 33 607-12

Hirsch F G, Texter E C, Wood L A, Ballard W C, Horan F E and Wright I S 1950 The electrical conductivity of blood I: relationship to erythrocyte concentration Blood 5 1017-35

Horesh L 2006 Some novel approaches in modelling and image reconstruction for multi-frequency electrical impedance tomography of the human brain UCL (University College London)

Hughes J R 2008 Gamma, fast, and ultrafast waves of the brain: Their relationships with epilepsy and behavior Epilepsy and Behavior 1325-31

Manwaring P K, Moodie K L, Hartov A, Manwaring K H and Halter R J 2013 Intracranial electrical impedance tomography: A method of continuous monitoring in an animal model of head trauma Anesthesia and Analgesia 117 866-75

Martini F H 1998 Fundamentals of Anatomy \& Physiology 4th edn. (London: Prentice Hall, Inc.)
Mohapatra SN and Hill D W 1975 The changes in blood resistivity with haematocrit and temperature European Journal of Intensive Care Medicine 1 153-62

Nunez P L and Srinivasan R 2006 Electric Fields of the Brain: The Neurophysics of EEG 2nd edn. (Oxford: Oxford University Press)

Pfützner H 1984 Dielectric analysis of blood by means of a rasterelectrode technique Med. Biol. Eng. Comput. 22 142-6

Ranck J B Jr. 1963 Specific impedance of rabbit cerebral cortex Exp. Neurol. 7 144-52

Ranck J Jr. and BeMent S L 1965 The specific impedance of the dorsal columns of cat: An anisotropic medium Exp. Neurol. $11451-63$

Sasaki K, Mizuno M, Wake K and Watanabe S 2015 Measurement of the dielectric properties of the skin at frequencies from 0.5 $\mathrm{GHz}$ to $1 \mathrm{THz}$ using several measurement systems 40 th International Conference on Infrared, Millimeter, and Terahertz Waves (IRMMW-THz) 40 (Hong Kong) 1-2

Schwan H P 1963 Electric characteristics of tissues: A survey Biophysik 1 198-208

Tamyis N M, Ghodgaonkar D K, Taib M N and Wui W T 2005 Dielectric properties of human skin in vivo in the frequency range 20-38 GHz for 42 healthy volunteers Proc. of the 28th URSI General Assembly 28, 1-4

Tang C, You F, Cheng G, Gao D, Fu F, Yang G and Dong X 2008 Correlation between structure and resistivity variation of the live human skull IEEE Trans. Biomed. Eng. 55 2286-92

Tsai B, Xue H, Birgersson E, Ollmar S and Birgersson U 2019 Dielectrical properties of living epidermis and dermis in the frequency range from $1 \mathrm{kHz}$ to $1 \mathrm{MHz}$ Journal of Electrical Bioimpedance 10 14-23

Wolf M, Gulich R, Lunkenheimer P and Loidl A 2011 Broadband dielectric spectroscopy on human blood Biochimica et Biophysica Acta-General Subjects $1810727-40$

Yamamoto T and Yamamoto Y 1976 Electrical properties of the epidermal stratum corneum Med. Biol. Eng. 14 151-8

Zhao T X, Jacobson B and Ribbe T 1993 Triple-frequency method for measuring blood impedance Physiol. Meas. 14 145-56

Zhbanov A and Yang S 2017 Electrochemical impedance spectroscopy of blood for sensitive detection of blood hematocrit, sedimentation and dielectric properties Anal. Methods93302-13 